\title{
UNMANNED AERIAL VEHICLE USED FOR REMOTE SENSING ON AN APULIAN FARM IN SOUTHERN ITALY
}

\author{
Simone Pascuzzi, Alexandros Sotirios Anifantis, Vincenzo Cimino, Francesco Santoro \\ University of Bari Aldo Moro, Italy \\ simone.pascuzzi@uniba.it
}

\begin{abstract}
Remote sensing applications within precision agriculture are mainly based on spectroscopy techniques, with the employment of optical sensors for the measurement of electromagnetic radiation at different wavelengths. Experimental evaluations of the physiological status of maize crops witha land area of about 4 ha on a farm located near the city of Lucera (Foggia province, Southern Italy) were carried out using an unmanned aerial vehicle (UAV) equipped with sensors able to acquire thermal, multispectral and RGB images. The UAV was programmed to follow a path specified by several waypoints and the images were acquired from a constant altitude of $70 \mathrm{~m}$ with a $70 \%$ overlap at a speed of $10 \mathrm{~m} \cdot \mathrm{s}^{-1}$. PixelWrench 2 software was used to reconstruct the acquired images and to assess the NDVI (Normalized Difference Vegetation Index). The analysis of the reflectance and emissivity did not highlight anomalies linked to likely incipient diseases, parasitic attacks or stress from nutritional deficiencies. The study of the images, however, pointed out a non-homogenous development of the plants in some zones most probably produced by a malfunction of the irrigation system. The thermal analysis confirmed this hypothesis. Further investigations carried out using UAV flights would be very useful to obtain a more detailed analysis of the state of the vegetation with a study of the temporal variability.
\end{abstract}

Keywords: unmanned aerial vehicle, multispectral sensor, thermal sensor, maize crop.

\section{Introduction}

Precision agriculture (PA) is an up-to-date technique that considers essential the analysis of the spatial variability of the soil and its influence on the crop production, exploiting the information connected with this variability to decide the most current management policy [1-3]. Precision agriculture is often used as a synonym of precision cultivation, applied to both herbaceous and treelike cropping systems, among which precision viticulture is particularly important in Italy [4-6].

The major phases of the PA are data gathering, field variability understanding and mapping, resolution taking, and the use of the management practices [7-9]. The information required by the PA to use the inputs in a variable rate way are provided by new technologies such as the global positioning system (GPS), remote sensing, geographic information systems (GIS), yield monitoring devices and so on $[10 ; 11]$.Therefore, the key problem of the PA is to gather information in order to plan and set up apposite resolution making systems and identify significant temporal fluctuations [12; 13]. In this context, particular attention has been paid in recent years to the development of devices for remote sensing, aimed at analysing the physiological state of the crops. However, over the past few years also the unmanned aerial vehicles (UAVs) have been subjected to significant development and are now suitable to be used as platforms to transport the aforementioned devices [13].In particular, by means of optical, multi-spectral and thermal sensors arranged on UAVs (also called drones), the reflectance and emissivity at various wavelengths may be analysed in order to calculate vegetation indices, such as the Normalized Difference Vegetation Index (NDVI), and investigate the spatial and temporal variability of the health of the crops [14]. Several studies were carried out to analyse the use of UAV for the PA. Among these, a correspondence between the NDVIand the applied nitrogen was evaluated for a sunflower crop using images acquired by a quadcopter[15]. Another system composed of a UAV equipped with a multispectral sensor and thermal camera enabled the assessment of the water stress levels in an irrigated vineyard and in a citrus grove [16-17]. Furthermore, a multispectral camera installed on an UAV was able to show and study a citrus greening disease within a citrus plantation [18]. In conclusion, the UAVs make it possible for high resolution images to be obtained and analysed in real time whilst also taking care to abide by operators' health and safety regulations[19-20].The aim of this study was the active assessment of a system composed of a drone equipped with sensors able to acquire thermal, multispectral and RGB images to analyse possible incipient diseases, parasitic attacks or stress from nutritional deficiencies of a maize crop located on a farm, where the organization and agronomic management is still carried out using traditional methods. Analysis of the acquired images with regards to the different wavelengths in relation to the values of the calculated NDVI index, produced interesting observations about the status of the maize crop under test, highlighting above all the usefulness of these current digital techniques. 


\section{Materials and Methods}

\section{Field equipment}

Experimental tests were carried out on a P0937 hybrid maizecrop covering4-hectaresof flat cultivable land located on a farm in the territory of Lucera (Foggia Province, Southern Apulia, Italy), as reported in Fig. 1 (the white line marks the boundaries).

The crop was divided into two sectors (north and south), each fitted with a traditional surface furrow irrigation system, according to the scheme shown in Fig.1. In particular, the pump positioned at the edge of the field ("a" in Fig.1) alternatively fed, through the main pipe "b", the tubes "c" and "d" placed at the top end of the furrows pertinent to the south and north sectors respectively.

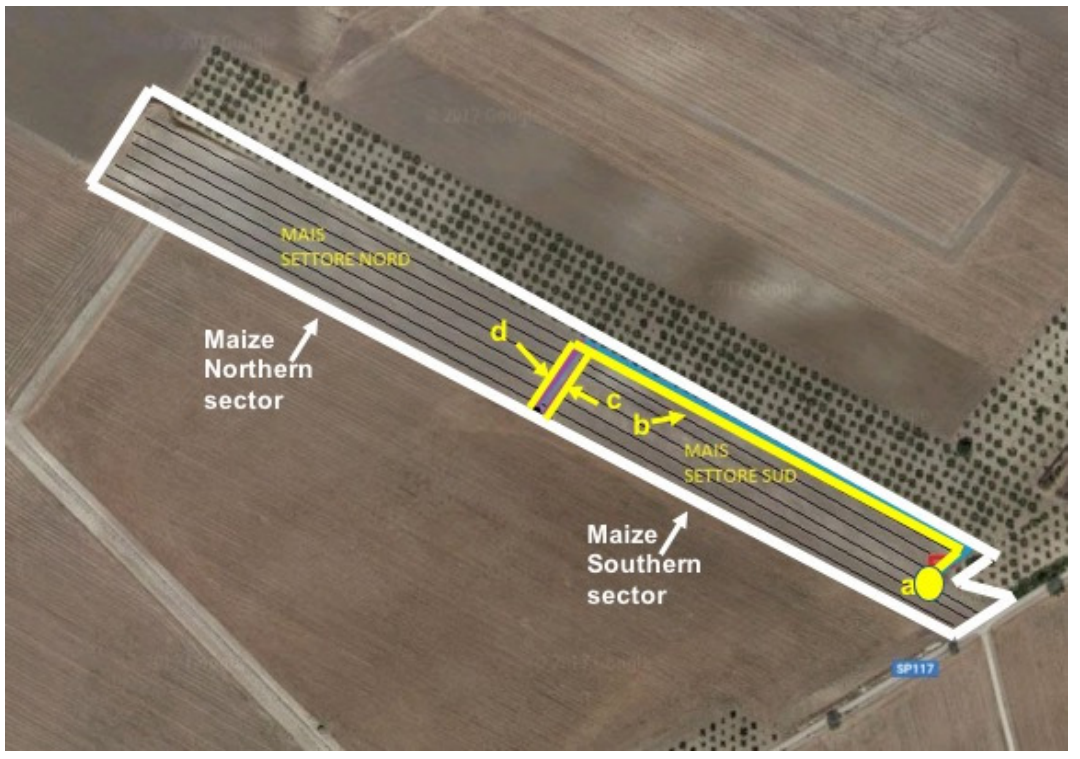

Fig. 1. Maize crop under test

Fig. 2 points out the developmental stage of the maize crop (phenological stage: V7)on the 21 June 2017, when the images were acquired.

The flight over the maize crop using the UAV took place immediately after the irrigation of the southern sector.

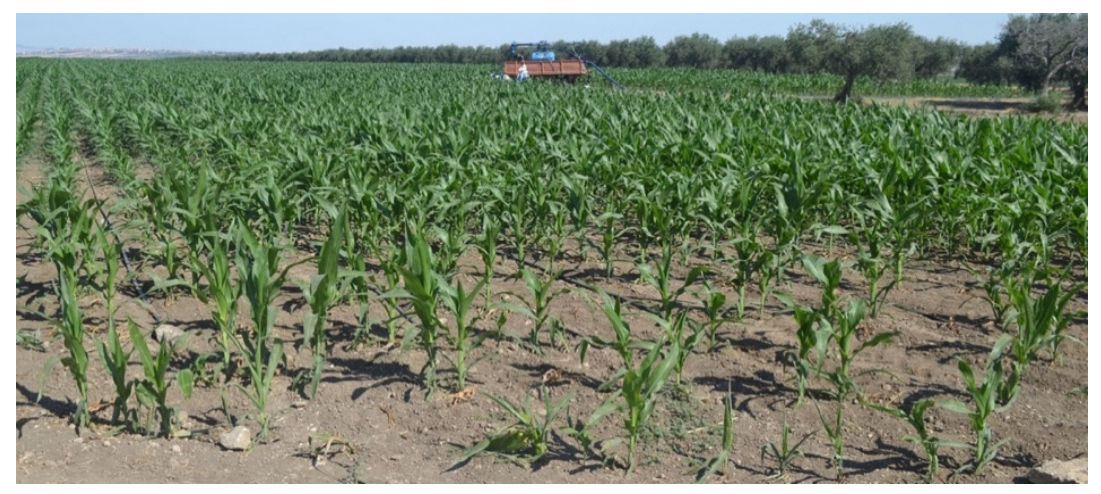

Fig. 2. Maize crop on $21^{\text {st }}$ June 2017 , day of the test

\section{Unmanned aerial vehicle and digital cameras employed}

The test was carried out using a quadcopter unmanned aerial vehicle (drone) with a frame composed of carbon fibreand airscrews of $457 \mathrm{~mm}$ (Adron Technology s.r.l., Udine, Italy). It was equipped with: a) RGB digital camera; b) Tetracam ADC snap digital camera (TETRACAM INC, Chatsworth, CA, USA); b) FLIRVUE ${ }^{\mathrm{TM}}$ pro thermal camera (Flir Systems Inc., Wilsonville, OR, USA) (Fig. 3a-3b). 


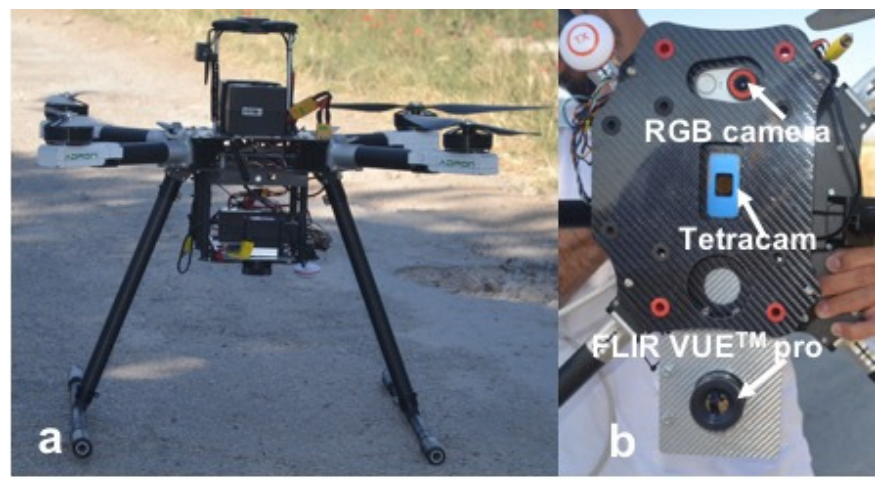

Fig. 3. Quadcopter used for the test (a); optical sensors on board (b)

The RGB images were acquired through a YI Action Camera (Shanghai, China)fitted with a 12 MP image sensor.

The Tetracam ADC (Agricultural Digital Camera) creates images with a resolution of 1280x1024 pixels and as known, the snap system, in contrast to the "Rolling Shutter" sensors, can expose the entire image at the same instant in time. This technique allows images to be captured free of motion blur and other distortions. The acquired images are in rws format, which is the snap shutter version of the raw files saved by other cameras. The Tetracam camera also contains the image editing software packagePixelWrench2 (TETRACAM INC, Chatsworth, CA, USA)for the reconstruction of colour in the rws images (de-mosaicking process). The following spectral bands were covered roughly after the colour reconstruction: 520-570 nm (green, $G$ ), 600-690 nm (red, $R$ ) and 750-850 nm (infrared, NIR).

The thermal camera FLIRVUE ${ }^{\mathrm{TM}}$ pro, fitted with an uncooled micro-bolometer as thermal imager, has are solution of 640x512 pixels and a spectral band within 7.5-13.5 $\mu \mathrm{m}$.

The drone was programmed to follow a path specified by several way points to have an overlap of $70 \%$ and the images were acquired from a constant altitude of $70 \mathrm{~m}$ at a speed of $4.8 \mathrm{~ms}^{-1}$. This technique produced a good resolution and a correction of the common refractive errors during the total mosaic phase.A white balance was performed before the flight in order to create a reference for the subsequent processing and analysis of the data, especially for multispectral images, which require maximum accuracy in reading the phenomena of vegetation reflectance.

The average air temperature during the drone flight was $37^{\circ} \mathrm{C}$.

\section{Image processing}

The use of PixelWrench2 software enabled georeferenced tiff images to be obtained after colour reconstruction of the rws images. Furthermore, this software permitted the assessment of the NDVI (Normalized Difference vegetation Index) through the following formula [11]:

$$
N D V I=\frac{N I R-\text { red }}{N I R+\text { red }}
$$

where NIR and red - the digital values of the pixel pertinent to the corresponding spectral bands.

Atmospheric effects (haze, dust or clouds), occurring during the acquisition of the images that could affect their brightness, were corrected and balanced by the aforesaid processing software.

\section{Results}

Figure 4 shows an image in the visible spectrum that highlights an area with reduced vegetative growth. This anomaly may present itself for different reasons, such as an excessive absorption of the soil, a nutritional deficiency or a failure of the irrigation system.Fig.4 also points out two probable holes in the main irrigation pipe ("b" pipe in Fig.1). The comparison between the NDVI index pertinent to the plants characterized by regular and poor vegetative development respectively was made to verify if nutritional characteristics would occur. Usually, these maize varieties are resistant to water stress and so this abnormal condition does not produce particular variations in the NDVI. 
Conversely, a strong difference in the NDVI would be visible in the case of under nourishment, due to the consequent reduction of the amount of chlorophyll produced.

The segmentation of the vegetated part of the ground was carried out in order to reduce any reading errors caused by the refraction of the vegetation other than the maize present in the photo, and then, error in the evaluation of the NDVI.

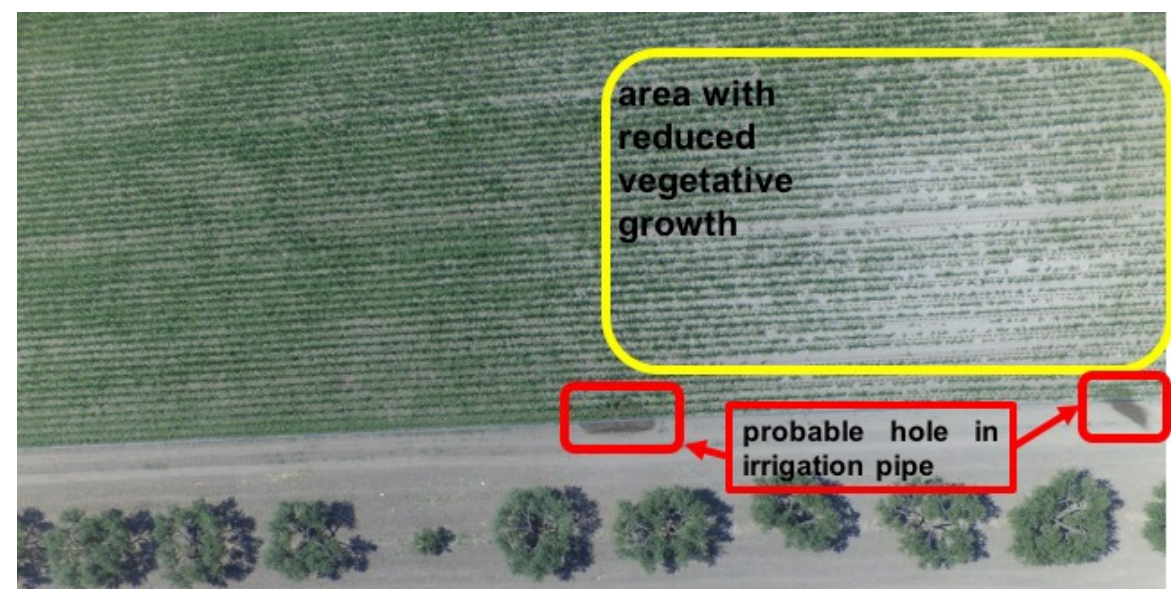

Fig. 4. Image that highlights area with reduced vegetative growth

The result of this analysis highlighted that the NDVI index corresponding to the area with the thickest canopy was 0.378 , a value that indicates a good vegetative condition. Conversely, also the NDVI index pertinent to the area with less developed plants, and so with more exposed ground, had a very similar value (0.337). This insignificant difference (about $12 \%$ ) between the two values suggests the exclusion of nutritional problems and that attention should be paid instead to the irrigation problems. The NDVI index of each sector of the crop, northern and southern respectively, was then assessed and they were compared to each other, taking into account that the northern sector was only irrigated during the acquisition of the images by the drone and that this could affect the data. Fig5a shows the NIR image comprising the two sectors, whereas Fig. $5 \mathrm{~b}$ reports the same processed image by the aforementioned software. Fig. 5b shows the clear difference in reflectance of the sectors. The NDVI index pertinent to the northern sector was 0.427 , whereas the one concerning the southern sector was 0.327 . This difference (about $23 \%$ ) could be due to several factors, such as the plants' high capacity to absorb water in a short time, the different variety of maize and the distinct spectral signature. Nevertheless, the multi-spectral analysis points out the good conditions of the entire crop, even in the zones witha large area of exposed soil probably due to a loss from the irrigation system.

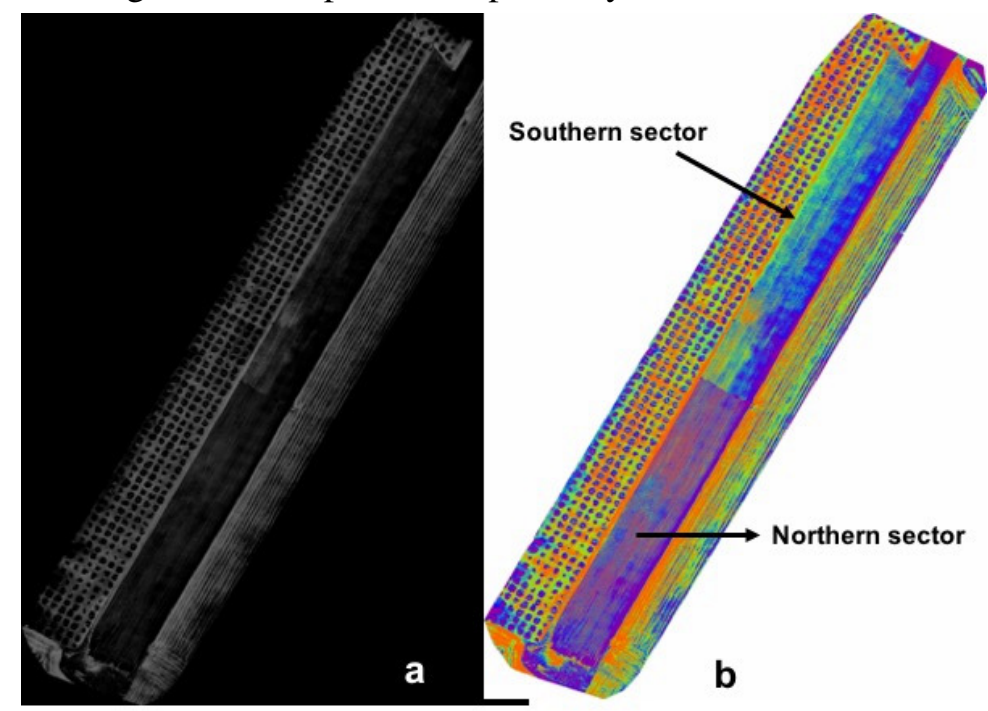

Fig. 5. NIR image comprising maize crop (a); processed image by software (b) 
Thermal detection is very useful, when there is a reason to suspect anomalies or a malfunction concerning the irrigation system, as was the case in question (Fig. 6). The soil and the furrows of the northern sector, which was irrigated during the UAV flight, had an average temperature of $34.0^{\circ} \mathrm{C}$. Conversely, the soil surrounding the two stains produced by holes on the main irrigation pipe (Fig. 4) had a temperature of $28.0^{\circ} \mathrm{C}$. This suggests that the water leak was so long-term that it decreased the soil temperature by $26.0^{\circ} \mathrm{C}$, if compared to that of the soil of the surrounding olive grove, and by $6.0^{\circ} \mathrm{C}$, if compared to the wet furrow. The average temperature of the non-irrigated soil of the surrounding olive orchard was $54.13^{\circ} \mathrm{C}$; whereas, inside the maize crop, where the irrigation worked well, the average temperature was $38.58^{\circ} \mathrm{C}$, and where it worked less satisfactorily, the average temperature was $42.24^{\circ} \mathrm{C}$. Furthermore, there is an area close to the tube "c" placed at the top end of the furrows of the southern sector (Fig. 1) with thermal anomalies probably linked to poor irrigation. The soil temperature of this area, highlighted in Fig. 6, is on average about $6-8{ }^{\circ} \mathrm{C}$ higher than that of the neighbouring zones. The other areas do not show any particular thermal anomalies.

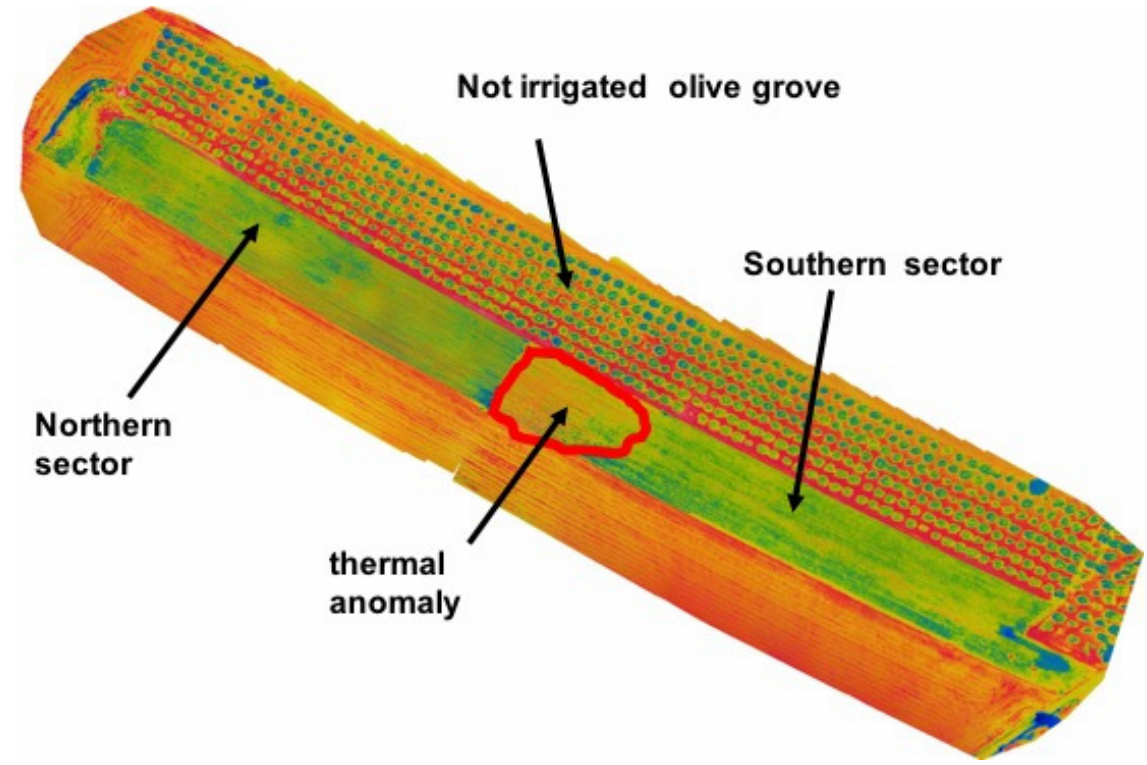

Fig. 6. Acquired image by thermal camera

\section{Conclusions}

The cultivation of maize subject to remote sensing through a UAV flight included a land area of about 4 ha. The analysis of the reflectance and emissivity at various wavelengths carried out by means of optical, multi-spectral and thermal sensors arranged on the drone does not highlight anomalies that could indicate incipient diseases, parasitic attacks or stress from nutritional deficiencies. However, the analysis of optical images points out a non-homogenous development of the plants in some zones that could be produced by a malfunction of the irrigation system, probably due to pressure drops inside the plumbing. The thermal analysis seems to confirm this hypothesis. Nevertheless, in order to improve the application of the management practices, further investigations carried out with other flights of the drone at different times and employing the same sensors would be very useful to obtain a more detailed analysis of the state of the vegetation with a study of the temporal variability.

\section{Acknowledgements}

The authors wish to thank Mr. M. Longo Ceo (Agritechno Srl, Torino), Mr. L. Zuliani and Mr. M. Picili (Adron Technology S.r.l., Udine, Italy) for their willingness and commitment in conducting the experimental tests. The authors also wish to thank the Cimino farm owner for his helpfulness and support with this research. All authors equally contributed to the present study.

\section{References}

[1] McBratney A. B., Whelan B. M., Shatar T. Variability and uncertainty in spatial, temporal and spatio-temporal crop yield and related data. In Precision agriculture: Spatial and temporal variability of environmental quality. Chichester: Wiley, 1997, pp. 141-160. 
[2] Brisco B., Brown R. J., Hirose T., Mcnairn H., Staenz K. Precision agriculture and the role of remote sensing: a review. Canadian Journal of Remote Sensing, vol. 24, 1998, pp. 315-327.

[3] Moran M. S., Inoue Y., Barnes, E. M. Opportunities and limitations for image-based remote sensing in precision crop management. Remote Sensing of Environment, vol. 61,1997, pp. 319-346.

[4] Pascuzzi S. The effects of the forward speed and air volume of an air-assisted sprayer on spray deposition in "tendone" trained vineyards. J. Agr. Eng., vol. 3, 2013, pp. 125-132. http://dx.doi.org/10.4081/jae.2013.e18

[5] Pascuzzi S., Santoro F. Analysis of the almond harvesting and hulling mechanization process: A case study. Agriculture (Switzerland), 7(12), 2017, $100 \mathrm{p}$. http://dx.doi.org/10.3390/agriculture7120100

[6] Baldoin C., Balsari P., Cerruto E., Pascuzzi S., Raffaelli M. Improvement in pesticide application on greenhouse crops: Results of a survey about greenhouse structures in Italy. Acta Hort. vol. 801, 2008, pp. 609-614.

[7] Seelan S. K., Laguette S., Casady G. M., Seielstad G. A.. Remote sensing applications for precision agriculture: a learning community approach. Remote Sensing of Environment, vol. 88, 2003, pp. 157-169.

[8] Lan Y., Thomson S. J., Huang Y., Hoffmann W. C., Zhang H. Current status and future directions of precision aerial application for site-specific cropmanagement in the USA. Computers and Electronics in Agriculture, vol. 74, 2010, pp. 34-38.

[9] Xiang H., Tian L. Method for automatic georeferencing aerial remote sensing (RS) images from an unmanned aerial vehicle (UAV) platform. Biosystems Engineering, vol.108, 2011, pp. 104-113.

[10] Pena-Barragan J. M., Lopez-Granados F., Jurado-Exposito M., Garcia-Torres L. Sunflower yield related to multitemporal aerial photography, land elevation and weed infestation. Precision Agriculture, vol. 11, 2010, pp. 568-585.

[11] Yang C., Bradford J. M., Wiegand C. L. Airborne multispectral imagery for mapping variable growing conditions and yields of cotton, grain sorghum, and corn. Transaction of ASAE, vol. 44, 2001, pp.1983-1994.

[12]Zhang C., Kovacs J. M. The application of small aerial systems for precision agriculture: a review. Precision Agriculture, vol. 13, 2012, pp. 693-712.

[13] Berni J.A.J., Zarco-Tejada P.J., Suarez L., Fereres E. Thermal and narrowband multispectral remote sensing for vegetation monitoring from unmanned aerial vehicle. IEEE Transactions on Geoscience and Remote Sensing, vol. 47, 2009, pp. 722-738.

[14] Corcoles J.I., Ortega J.F., Hernandez D., Moreno M.A.Estimation of leaf area index in onion (Allium cepa L.) using an unmanned aerial vehicle. Biosystems Engineering, vol. 115, 2013, pp. 31-42.

[15] Vega F.A., Ramírez F.C., Saiz M.P.,Rosúa F.O. Multitemporal imaging using an unmanned aerial vehicle for monitoring a sunflower crop. Biosystems Engineering, vol. 132, 2015, pp. 19-27.

[16] Baluja J., Diago M. P., Balda P., Zorer R., Meggio F., Morales F., Tardaguila J. Assessment of vineyard water status variability by thermal and multispectral imagery using an unmanned aerial vehicle (UAV). Irrigation Science, vol. 30, 2012, pp. 511-522.

[17] Manetto G., Cerruto E., Pascuzzi S., Santoro F. Improvements in citrus packing lines to reduce the mechanical damage to fruit. Chem. Eng. Trans. 58, 2017, pp. 391-396, http://dx.doi.org/10.3303/CET1758066

[18] Garcia-Ruiz F., Sankaran S., Maja J. M., Lee W. S., Rasmussen J., \& Ehsani R. Comparison of two aerial imaging platforms for identification of Huanglongbing-infected citrus trees. Computers and Electronics in Agriculture, vol. 91, 2013, pp. 106-115.

[19]Zarco-Tejada P. J., Ustin S. L., Whiting M. L. Temporal and spatial relationships between withinfield yield variability in cotton and high-spatial hyperspectral remote sensing imagery. Agronomy Journal, 97, 2005, pp. 641-653.

[20] Pascuzzi S. A multibody approach applied to the study of driver injuries due to a narrow-track wheeled tractor rollover. J. Agr. Eng., vol. 46, 2015, pp. 105-114.

http://dx.doi.org/10.4081/jae.2015.466 